\title{
Unmet Expectations: Why Is There Such A Difference Between Student Expectations And Classroom Performance?
}

Terrye A. Stinson, Southern Arkansas University Xiaofeng Zhao, Southern Arkansas University

\begin{abstract}
Past studies indicate that students are frequently poor judges of their likely academic performance in the classroom. The difficulty a student faces in accurately predicting performance on a classroom exam may be due to unrealistic optimism or may be due to an inability to self-evaluate academic performance, but the resulting disconnect between expectations and reality can be very discouraging to students and may lead to early attrition. This paper studies undergraduate business students and investigates differences between scores they predicted earning on final exams and scores actually earned. Results indicate that the average student will overestimate an exam score by over five points. Results also indicate that freshmen students, and students with low cumulative grade point averages are likely to overestimate exam scores by the equivalent of a letter grade. Understanding this phenomenon may help educators deal with discouraged students and provide opportunities for faculty to create a learning environment that reduces attrition and ultimately increases student success and graduation rates.
\end{abstract}

Keywords: Students, Grades, Expectations, Unrealistic Optimism, Attrition

\section{INTRODUCTION}

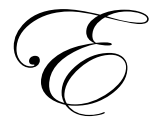

ducators are keenly aware of the importance attached to students' grades as an indicator of ability and aptitude. Some students seem to share concern over grades, while others do not. Whether truly concerned over final grades or not, many students seem to be poor judges of their likely performance on pending examinations. Some studies suggest that students have unrealistic optimism about the outcome; other studies suggest that students, particularly weak students, are simply too incompetent to judge their own performance. The purpose of this study is to analyze the ability of students to predict their own test grades and to seek explanations which might help an instructor understand students' reactions to unexpected grades.

\section{LITERATURE REVIEW}

Studies and research on individual self-assessment provides a basis for understanding students' perceptions of their own academic competence. In general, people tend to overestimate their abilities. Perhaps the best illustration of this tendency is the "better-than-average effect." A wide body of literature suggests that most people believe that they are more intelligent, organized, ethical, logical, interesting, fair-minded, healthy, and/or attractive than the average person. This "better-than-average effect" has been widely observed among student populations. For example, the College Board surveyed one million high school students in 1977; the results of this study show perhaps the most extreme documentation of this effect. Discussing the study, Dunning, Meyerowitz, and Holtzberg (1989) noted,

When rating themselves vis-à-vis their peers, 70 percent rated themselves as above average in leadership ability whereas only 2 percent judged themselves as below average. When considering athletic ability, 60 percent considered themselves above the median and only 6 percent below. When asked to judge their ability to get along 
with others, all students rated themselves as at least average, 60 percent placed themselves in the top 10 percent and 25 percent placed themselves in the top first percentile. (1082)

A number of theories attempt to explain this phenomenon of overestimation. These explanations include the level of individual information-processing characteristics, such as metacognitive skills, (Kruger and Dunning, 1999 and Kennedy, Lawton, and Plummee, 2002) and personality traits, such as idiosyncratic definitions of competence (Dunning, Meyerowitz, and Holtzberg, 1989) and desire for self-enhancement (Alicke et al., 1995; Brown and Gallagher, 1992).

\section{Incompetence Theory}

Kruger and Dunning (1999) and Kennedy, Lawton, and Plummee (2002) propose that the reason people overestimate their abilities may lie in their incompetence. The skills that develop competence in a particular domain are often the same skills necessary to evaluation competence in that area. Therefore, unskillful people "don't know what they don't know," and they are unable to recognize their true level of incompetence. In a study to explain the overestimation of student grade, Kennedy, Lawton and Plummee show that the overestimation is negatively related to students' actual scores, with the students in the lowest quartile of performance overestimating the most. Koku and Qureshi (2004) show that high-performing students discriminated better between difficult and easy multiple-choice questions than did low-performing students. (This explanation of the overestimation is referred to as the incompetence theory throughout this paper.)

Clayson (2005) says that there are problems with the competency interpretation of student overconfidence. For instance, the direction of error is not obvious. Incompetent students could overestimate as well as underestimate their performance. He analyzed the correlation between metacognitive variables with student overestimation and found no evidence that the overestimation was due to lack of cognitive competence. He concluded that it appears to be a systematic effect, perhaps determined by a student's experiences and expectations.

Kennedy, Lawton, and Plummee (2002), however, showed that poorer students overestimate their performance while better students underestimated their performance. They argue that poorer students don't know what they don't know and have neither a particular skill nor the cognitive ability to judge their own achievement. Consequently, such students are unlikely to realize their limitations and more likely to overestimate their performance. On the other hand, high performers know what they don't know. These students may not recognize their ability to be successful and are more likely to underestimate their grades.

\section{Unrealistic Optimism Theory}

Various data suggest that people tend to be unrealistically optimistic. For example, surveys concerning automobile accidents (Robertson, 1977) and crime (Weinstein, 1980) find many people say their risk is less than average but few say their risk is greater than average. Psychologists suggest that people tend to be unrealistically optimistic that positive events will happen and that negative events will not. (This explanation of overestimation is referred to as the unrealistic optimism theory throughout this paper.)

Some studies find that business students overestimate their examination scores in individual classes. For example, when examining metacognitive skills of students in a large macroeconomics class, Grimes (2002) found that pretest expectation exceeded performance score in the regularly scheduled midterm examination by almost 13 points while the difference between posttest prediction and actual grade declined to 7 points. Grimes attributed the student overconfidence to unmet student expectations.

\section{Consequences Of Unmet Expectations}

Numerous studies (e.g. Newlon and Gaither, 1980; Tinto, 1993; and Murtaugh, Burns, and Schuster, 1999) find that students tend to drop out in their first two years in college, particularly in the first year. Poor grade are one of the most important reasons (e.g. Astin, 1975 and Mangum, Baugher, Winch, and Varanelli, 2005). Unmet 
expectations of freshmen also may be an important cause of high attrition. As faculty members, we often hear students say, "I thought I did better." When students receive a grade, which is lower than they anticipated, it frustrates them. They may blame external factors or the instructor's teaching style for their grade, but an important factor may be their own unrealistic expectations.

Management studies show that by reducing unrealistic expectations new employees can better handle difficulties that arise in new job situations (Fedor, Buckley, and Davis, 1997). Similarly, Clayson (2005) investigated the effect of realigning student performance expectation. He instructed students early in selected courses that certain academic standards would be required, regardless of the standards of any other class. In addition, he used early testing to reinforce his conditions. He found that students in these classes expected a course average grade of 2.70, while actually received a grade of 2.85 . However, other undergraduate classes taught during the same time period expected a grade of 2.69 on average and received 2.25. Clayson suggests that faculty and institutions establish and communicate appropriate grading norms help students develop realistic expectations.

\section{DATA COLLECTION}

This study evaluated students taking the final examination in 25 business classes and analyzed their expectations, actual performances, and relative errors in estimation. Data were collected during the final week of the spring semester 2006 at a regional state university. A survey was given to 25 classes taught by 12 business instructors at the College of Business at the beginning of final exams. Enrollment in each class was relatively small, ranging from 9 to 36 students per class. After excluding incomplete or illegible surveys, 555 responses from 373 students were analyzed. Almost all of the respondents are business majors or minors. (Ten respondents were enrolled in an economics course that satisfied a general education requirement.)

Among the 373 respondents, 243 students participated in the survey once, 84 students participated twice while taking different tests, 40 answered three times, and 6 answered four times. When students took multiple surveys, the demographic information was the same but their predictions on the final tests and actual scores differed. Therefore, surveys from the same respondent are different and are treated independently. Hereafter, each response will be called a student-test.

The data gathered from the survey included student demographic information and the score (between 0 and 100) the student expected to receive on the final test. Instructors provided actual scores earned on the final test. The study also used the cumulative GPA for each student retrieved from the university's database.

\section{ANALYSIS OF DATA}

On average, students participating in the study expected to score 81.67 points on their final examinations but actually earned 76.12 points. That is to say, a typical business student overestimated his/her final score by 5.55 points. This overestimation is statistically significant at a one percent level. The magnitude of student overprediction found in this study is smaller than the difference Grimes (2002) reported. The time of data collection may explain this difference. Grimes studied test-takers in a midterm exam while we analyzed students in final tests. (According to Kennedy et al. (2002) and Kruger and Dunning (1999), students tend to develop better expectation-performance congruence as the academic term progresses.)

Figure 1 on the following page shows the distribution of overestimation of final scores in the 555 studenttests. In total, 344 tests $(62 \%)$ were overestimated, $183(33 \%)$ were underestimated, and 28 students (5\%) precisely predict their final scores. No students accurately estimate their scores on more than one test. Individual student overprediction was as large as 60 points, and one student underestimated her final score by 25 points. Figure 1 also shows that that the estimation error of 102 student-tests (18.5\%) was within \pm 2 points. There were 79 student-tests $(14.23 \%)$ overestimated by more than 17 points while only 11 student-tests $(1.98 \%)$ were underestimated by more than 17 points. It appears that students are more likely to overpredict than underpredict their performance. 


\section{Analysis Of Outliers}

Refining this analysis, the 79 student-tests which were overestimated by more than 17 points were excluded from the analysis. After which, the rest of sample still overpredicted their final scores by an average of 2.03 points, which remains statistically significant at the one percent level. This indicates that overall student overestimation is not due to a few extremely large estimation errors. Rather, it seems it is a pervasive phenomenon and is consistent with the unrealistic expectation theory.

Among the 555 responses, 59 students failed on 63 tests (11.35\%). These 59 students expected to make 74.65 points but only earned 50.17 points, resulting in overestimation of 24.48 points. It appears these students are excessively optimistic as Grimes (2002) suggests, and while aware of how they are doing, these students believe they will perform at a different level. (Only one student predicted to fail her test. She estimated a score of 50 and made 43.) Redefining the analysis, the 63 failed exams were excluded from the study. After which, the rest of respondents still overpredicted their scores by 3.13 points, which is statistically significant from zero at the one percent significance level.

Figure 1

Distribution of Student Expectation Errors

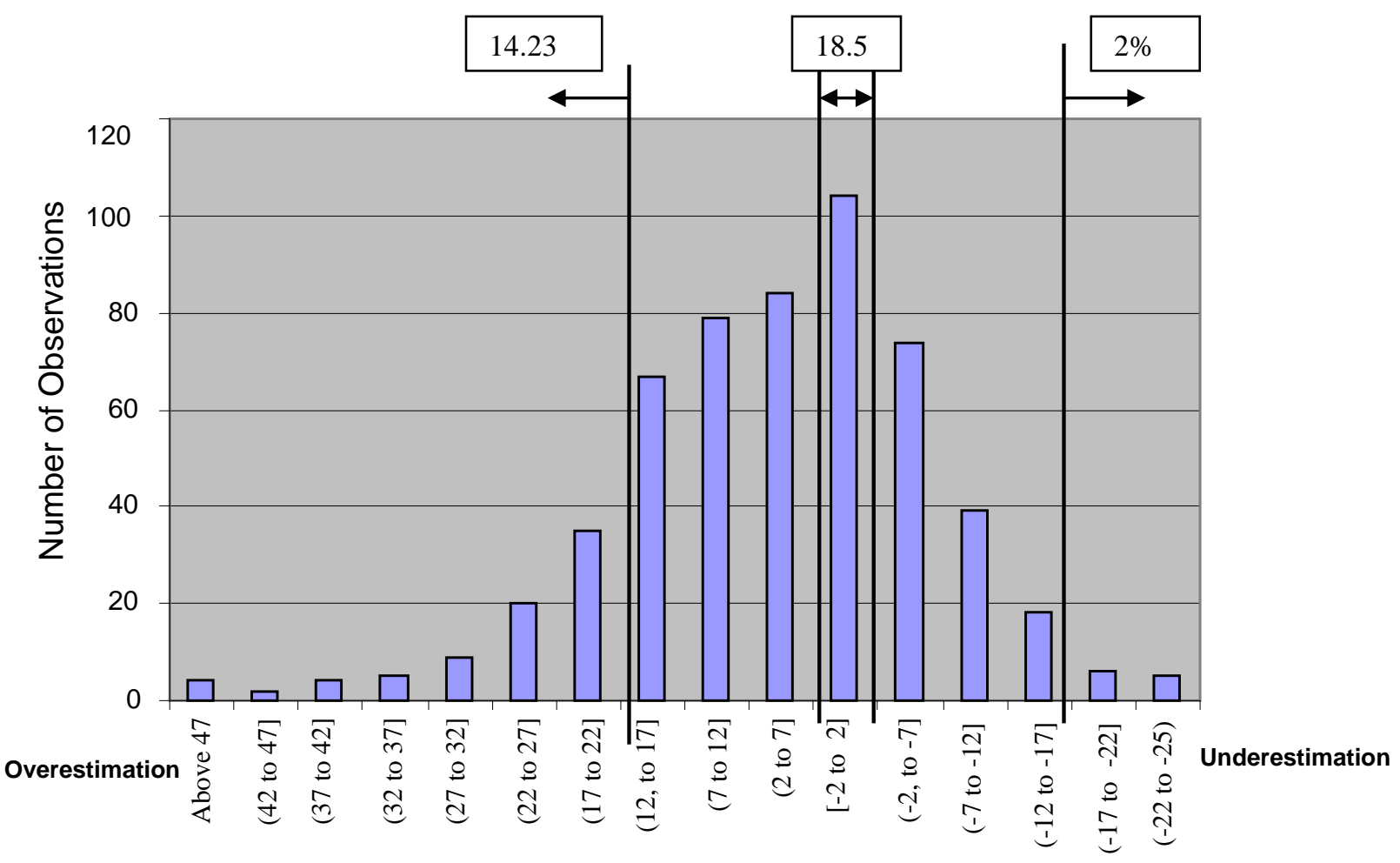

Note: The horizontal axis represents the range of the student under/overestimation. The positive number indicates overestimation and the negative number means underestimation. The [square bracket] indicates included bound and the (parenthesis indicates) indicates that bound is not included.

In the study, 16 respondents predicted scoring 100 percent on their finals. Their actual scores, however, range from 40 to 100 , with only one scoring 100 and only 4 earning more than 90 points. The actual average score for these students was 80.13 . This result may have been affected by students' attitude. (Some students may have not 
taken the survey seriously.) Excluding these 16 student-tests from the study, the recomputed average overestimation was still 5.13 points, which is statistically significant at one percent level.

Eliminating both outliers, the students who failed and the student who predicted perfect scores, does not change the significance of the findings. After their exclusion 478 responses remained, and the average estimation was reduced to 2.78 points, which is still statistically significant from zero at one percent level.

\section{Analysis Of Class Averages}

The class average scores of the 25 classes surveyed are presented in Table 1 on the following page. The expected final scores are substantially different among classes, ranging from 76.82 to 87.73 . This indicates that students perceived differences in the degree of difficult on their final exams. In 21 out of 25 classes, the average predicted grade exceeded the predicted score (overestimation). Particularly, in 11 classes, the expectation and performance score differed by more than 8 points. In the other 4 classes, the average predicted grade was less than the average actual grade (underestimation). This underestimation was statistically significant in only one of these four classes and in the other 3 classes, students underpredicted their scores by only 2 points.

\begin{tabular}{|c|c|c|c|c|c|c|c|}
\hline \multicolumn{8}{|c|}{$\begin{array}{c}\text { Table 1 } \\
\text { Average Scores in Classes Surveyed }\end{array}$} \\
\hline \multirow[b]{2}{*}{ Instructor } & \multirow[b]{2}{*}{ Class } & \multirow[b]{2}{*}{ Number of Obs } & \multicolumn{3}{|c|}{ Mean Score } & \multicolumn{2}{|c|}{ Test for zero overprediction } \\
\hline & & & Expectation & Actual & Overprediction & t-value & p-value \\
\hline \multirow[t]{3}{*}{ T1 } & $\mathrm{C} 1$ & 22 & 76.82 & 82.73 & -5.91 & -3.96 & 0.0007 \\
\hline & $\mathrm{C} 2$ & 18 & 81.61 & 71.22 & 10.39 & 2.50 & 0.0229 \\
\hline & Both & 40 & 78.98 & 77.55 & 1.43 & 0.60 & 0.5551 \\
\hline $\mathrm{T} 2$ & $\mathrm{C} 3$ & 22 & 85.55 & 78.36 & 7.19 & 2.94 & 0.0079 \\
\hline $\mathrm{T} 3$ & $\mathrm{C} 4$ & 19 & 85.79 & 77.68 & 8.11 & 3.07 & 0.0066 \\
\hline $\mathrm{T} 4$ & $\mathrm{C} 5$ & 35 & 81.03 & 72.46 & 8.57 & 5.68 & $<.0001$ \\
\hline \multirow[t]{3}{*}{ T5 } & C6 & 15 & 85.47 & 71.13 & 14.34 & 3.45 & 0.0039 \\
\hline & $\mathrm{C} 7$ & 22 & 85.64 & 73.41 & 12.23 & 4.41 & 0.0002 \\
\hline & Both & 37 & 85.57 & 72.49 & 13.08 & 5.62 & $<.0001$ \\
\hline T6 & C8 & 28 & 80.00 & 82.07 & -2.07 & -0.98 & 0.3364 \\
\hline $\mathrm{T} 7$ & C9 & 26 & 87.73 & 86.77 & 0.96 & 0.59 & 0.5603 \\
\hline \multirow[t]{4}{*}{$\mathrm{T} 8$} & $\mathrm{C} 10$ & 24 & 80.38 & 70.38 & 10.00 & 4.62 & 0.0001 \\
\hline & C11 & 20 & 80.00 & 82.30 & -2.30 & -1.23 & 0.2326 \\
\hline & $\mathrm{C} 12$ & 18 & 83.83 & 73.22 & 10.61 & 5.57 & $<.0001$ \\
\hline & All & 62 & 81.26 & 75.05 & 6.21 & 4.51 & $<.0001$ \\
\hline \multirow[t]{5}{*}{ T9 } & $\mathrm{C} 13$ & 24 & 81.13 & 77.71 & 3.42 & 1.03 & 0.3153 \\
\hline & C14 & 23 & 82.43 & 84.43 & -2.00 & -0.80 & 0.4315 \\
\hline & $\mathrm{C} 15$ & 11 & 82.09 & 78.73 & 3.36 & 1.28 & 0.2303 \\
\hline & $\mathrm{C} 16$ & 18 & 83.78 & 79.28 & 4.50 & 1.88 & 0.0770 \\
\hline & All & 76 & 82.29 & 80.26 & 2.03 & 1.38 & 0.1723 \\
\hline \multirow[t]{3}{*}{ T10 } & C17 & 19 & 79.37 & 75.11 & 4.26 & 2.16 & 0.0448 \\
\hline & $\mathrm{C} 18$ & 22 & 79.23 & 69.82 & 9.41 & 4.49 & 0.0002 \\
\hline & Both & 41 & 79.29 & 72.27 & 7.02 & 4.72 & $<.0001$ \\
\hline \multirow[t]{4}{*}{ T11 } & C19 & 25 & 80.80 & 79.12 & 1.68 & 1.18 & 0.2483 \\
\hline & $\mathrm{C} 20$ & 9 & 82.78 & 71.89 & 10.89 & 3.19 & 0.0129 \\
\hline & $\mathrm{C} 24$ & 11 & 81.36 & 74.55 & 6.81 & 2.76 & 0.0200 \\
\hline & All & 45 & 81.33 & 76.56 & 4.77 & 3.68 & 0.0006 \\
\hline \multirow[t]{5}{*}{ T12 } & C22 & 22 & 77.86 & 70.86 & 7.00 & 2.58 & 0.0173 \\
\hline & $\mathrm{C} 23$ & 32 & 78.78 & 72.75 & 6.03 & 2.27 & 0.0305 \\
\hline & $\mathrm{C} 24$ & 34 & 79.35 & 70.62 & 8.73 & 3.45 & 0.0015 \\
\hline & $\mathrm{C} 25$ & 36 & 83.36 & 75.69 & 7.67 & 3.54 & 0.0012 \\
\hline & All & 124 & 80.10 & 72.69 & 7.41 & 5.96 & $<.0001$ \\
\hline \multicolumn{3}{|c|}{ Test for equality among instructors (p-value) } & $<0.0001$ & 0.0001 & $<0.0001$ & & \\
\hline
\end{tabular}


Based on the data in Table 1, it appears that there is an overall pervasive overestimation of student performance. More than 60 percent of student-tests are overestimated while about $33 \%$ are underestimated. All but one student predicted that they would pass the final exam even though more than 11 percent of students in fact failed the exam. In the majority of classes, students believe they did better than what their scores show. This overconfidence cannot be attributed to a few possible excessive estimation errors. This finding is consistent with the unrealistic optimism theory.

\section{Analysis Of Demographic Differences}

Data collected in this study was analyzed to search for differences that could be attributed to demographic characteristics. Few differences in student overestimation of final scores were found among groups categorized by demographic characteristics. Table 2 on the following page presents mean expectation, performance grade, and student overestimation among different groups.

\begin{tabular}{|c|c|c|c|c|c|}
\hline \multicolumn{6}{|c|}{$\begin{array}{c}\text { Table } 2 \\
\text { Student Over-prediction of Final Scores Among Different Groups }\end{array}$} \\
\hline \multirow[b]{2}{*}{ Group } & \multirow{2}{*}{$\begin{array}{l}\text { Number } \\
\text { of Obs }\end{array}$} & \multicolumn{3}{|c|}{ Mean Score } & \multirow{2}{*}{$\begin{array}{c}\text { Test for equality of } \\
\text { overprediction (p-value) }\end{array}$} \\
\hline & & Expectation & Actual & Overprediction & \\
\hline \multicolumn{6}{|l|}{ Classification } \\
\hline Freshman & 43 & 83.98 & 74.19 & 9.79 & \multirow{4}{*}{$\begin{array}{c}\text { ANOVA } \\
\text { F-value }=2.02 \\
\text { p-value }=0.1103\end{array}$} \\
\hline Sophomore & 107 & 81.92 & 77.54 & 4.38 & \\
\hline Junior & 240 & 82.22 & 76.98 & 5.24 & \\
\hline Senior & 165 & 80.78 & 75.25 & 5.53 & \\
\hline \multicolumn{6}{|l|}{ Status } \\
\hline Traditional & 467 & 81.65 & 76.14 & 5.51 & \multirow{2}{*}{$\begin{array}{c}\mathrm{t} \text {-value }=0.19 \\
\mathrm{p} \text {-value }=0.8500\end{array}$} \\
\hline Nontraditional & 88 & 81.80 & 76.01 & 5.79 & \\
\hline \multicolumn{6}{|l|}{ Gender } \\
\hline Male & 287 & 81.47 & 76.10 & 5.37 & \multirow{2}{*}{$\begin{array}{c}\mathrm{t} \text {-value }=0.36 \\
\mathrm{p} \text {-value }=0.7198\end{array}$} \\
\hline Female & 268 & 81.89 & 76.14 & 5.75 & \\
\hline \multicolumn{6}{|l|}{ Race } \\
\hline White & 356 & 81.48 & 76.96 & 4.52 & \multirow{4}{*}{$\begin{array}{c}\text { ANOVA } \\
\text { F-value }=3.68 \\
\text { p-value }=0.0121\end{array}$} \\
\hline Black & 137 & 80.68 & 72.20 & 8.48 & \\
\hline Asia & 38 & 87.05 & 83.16 & 3.89 & \\
\hline Other & 24 & 81.79 & 74.96 & 6.83 & \\
\hline \multicolumn{6}{|l|}{ Birth Place } \\
\hline U.S. & 482 & 81.16 & 75.58 & 5.58 & \multirow{2}{*}{$\begin{array}{c}\mathrm{t} \text {-value }=0.15 \\
\mathrm{p} \text {-value }=0.8809\end{array}$} \\
\hline Other countries & 73 & 85.07 & 79.68 & 5.39 & \\
\hline \multicolumn{6}{|l|}{ Study Time } \\
\hline$>2.5$ hours & 318 & 81.94 & 76.41 & 5.53 & \multirow{2}{*}{$\begin{array}{c}\mathrm{t} \text {-value }=0.04 \\
\mathrm{p} \text {-value }=0.9677\end{array}$} \\
\hline$\leq 2.5$ hours & 237 & 81.32 & 75.74 & 5.58 & \\
\hline$>4$ hours & 131 & 82.80 & 77.56 & 5.23 & \multirow{2}{*}{$\begin{array}{c}\mathrm{t} \text {-value }=0.01 \\
\mathrm{p} \text {-value }=0.9942\end{array}$} \\
\hline$<1$ hours & 41 & 80.63 & 75.41 & 5.22 & \\
\hline \multicolumn{6}{|c|}{ GPA (All classes) } \\
\hline 2.5 and blow & 152 & 78.05 & 67.70 & 10.35 & \multirow{4}{*}{$\begin{array}{c}\text { ANOVA } \\
\text { F-value }=19.87 \\
\text { p-value }<.0001\end{array}$} \\
\hline$(2.5,3.0]$ & 139 & 80.40 & 72.77 & 7.63 & \\
\hline$(3.0,3.5)$ & 144 & 82.92 & 80.12 & 2.80 & \\
\hline$(3.5,4.0)$ & 120 & 86.25 & 85.88 & 0.37 & \\
\hline \multicolumn{6}{|c|}{$\begin{array}{l}\text { GPA (Classes with a } \\
\text { difficult final) }\end{array}$} \\
\hline 2.5 and blow & 49 & 78.98 & 63.24 & 15.74 & \multirow{4}{*}{$\begin{array}{c}\text { ANOVA } \\
\text { F-value }=7.96 \\
\text { p-value }<.0001\end{array}$} \\
\hline$(2.5,3.0]$ & 68 & 80.15 & 68.93 & 11.22 & \\
\hline$(3.0,3.5]$ & 50 & 83.40 & 75.82 & 7.58 & \\
\hline$(3.5,4.0)$ & 49 & 86.43 & 81.43 & 5.00 & \\
\hline
\end{tabular}


Freshmen expected to earn the highest average scores but made the lowest average. On average, freshmen predict to earn 83.98 in their final exams compared to $81.92,82.22$, and 80.78 estimated by sophomores, juniors, and seniors, respectively. However, freshmen made only 74.19, a lower grade than that earned by their counterparts (77.54, 76.98, and 75.25 respectively).

Combining the effect of their high expectation and low performance, freshmen exhibited the largest overestimation of 9.79. Sophomores, juniors, and seniors overpredicted their final performance by 4.38, 5.24, and 5.53 , respectively. In other words, freshmen overpredicted their final score by almost a letter grade, while more experienced students overpredicted their final score by about half of a letter grade.

Freshmen also spend less time preparing for the final exam, studying 3.07 hours before the final while sophomores, juniors, and seniors spend $3.47,3.64$, and 3.74 hours, respectively. Data in this study show that the more students study, the less likely they are to overpredict their final scores.

Traditional students expected to make 81.65 in their final tests and earned 76.14, an overestimation of 5.51 points. Non-traditional students expected to make 81.80 and earned 76.01, an overestimation of 5.79 points. Nontraditional students did not expect to earn more, actually made slightly less, and overpredicted their final scores as much as their traditional classmates.

In this study, male students expected to make 81.47 , which is slightly lower than 81.89 predicted by their female counterparts. Male students made 76.10 with the overestimation being 5.37 points, while female students earned an average of 76.14, which is 5.75 points lower than the expectation. The expectation, performance score, and overestimation are not significantly different between male and female students

Some differences may be attributable to race. Asian students with the highest average GPA of 3.34 expected to make 87.05 (an estimate that was higher than that predicted by any other ethnical group). The Asian students also performed best at 83.16, resulting in the lowest overestimation of 3.89. Black students had the lowest average GPA (2.69); they expected to make the lowest grade of 80.68 and indeed underperformed other students by earning an average of 72.20. Black students, however, also showed the strongest tendency to overestimate their grade. Their performance score exceeded their expectation by as many as 8.48 points. One-way analysis of variance shows that the difference of overestimation among races is significantly different at a 5 percent significance level.

The majority of study subjects were born and raised in the United States. They predicted to earn 81.16, which is 3.91 points lower than the expectation of 85.07 by international students. American students, on average earning 75.58, also underperformed international students, who made 79.68. Both groups overpredicted their performance, but the magnitude of overprediction is about the same.

Students' expectation, actual performance, and overestimation seem to have nothing to do with their selfreported study time. For an initial analysis, respondents were divided into two groups - those who studied more than 2.5 hours and those who studies 2.5 hours and less. On average, students studying more than 2.5 hours predicted to make a slightly higher grade, actually earned slightly more, and were slightly less overoptimistic than other students. For further analysis, respondents were divided into students studying more than 4 hours and student who spent less than 1 hour studying. Both groups overpredicted their grades by about the same amount.

Finally, expectations and results were analyzed based on students' GPAs. There appears to be significant difference between academically strong and academically weak students in terms of expectation, actual performance and overestimation of final exams. Respondents were divided into four groups based on their cumulative GPA as follows: 2.5 and below, 2.5 to $3.0,3.01$ to 3.5 , and 3.51 to 4.0. Each group has roughly one fourth of total observations. Our data shows that, as the GPA increases, student expectations and actual performance scores increase while the overestimation decreases.

The group of students with the lowest GPA ( 2.5 and below) expected to make 78.05 but actually earned 67.4, an overprediction of 10.35 points (or more than a letter grade). In contrast, the group of students with the 
highest of GPA expected to earn 86.25 and actually made 85.88 . They collectively almost accurately predicted their performance with an overestimation of merely 0.37 points.

In light of the observed differences, respondents' expectations and actual results were analyzed to determine which combination of factors apparently contributes most significantly to overestimation. Using regular linear regression, the following model was formulated:

$$
\begin{aligned}
& \text { Overestimation }=\alpha_{0}+\alpha_{1} \text { GPA }+\alpha_{2} \text { Freshman }+\alpha_{3} \text { Sophomore }+\alpha_{4} \text { Junior }+\alpha_{5} \text { Traditional }+ \\
& \alpha_{6} \text { Female }+\alpha_{7} \text { White }+\alpha_{8} \text { Black }+\alpha_{9} \text { Asia }+\alpha_{10} \text { US }+\alpha_{11} \text { Study time }
\end{aligned}
$$

In this model, GPA and study time are continuous variables. Freshman, sophomore, junior, traditional, female, white, black, Asian, and US are all dummy variables. The regression results are shown in Table 3 on the following page. Model 1 shows that, among 11 independent variables, only GPA and freshman are significant at a one percent significance level in explaining the variation of student overestimation. If all insignificant variables are excluded from the analysis, model 2. shows that GPA and freshman are still significant at one percent level. The coefficient of the variable GPA stays about the same. The coefficient of the variable freshman changed marginally. The intercept increased from 27.99 to 24.77 and changed by 3.22. However, the adjusted R-square improved slightly from 11.88 percent to 12.11 percent. As evidenced by the adjusted R-square, the variables GPA and freshman explain only about 12 percent of the variation of the dependent variable. Therefore, all other student characteristic variables, except GPA and the dummy variable freshman, do not affect student overestimation; apparently some other factors also have an impact on student over-optimism.

\begin{tabular}{|l|c|c|}
\hline \multicolumn{3}{|c|}{ Table 3 } \\
\hline \multicolumn{1}{|c|}{ Multivariate Analysis of Student Overestimation } \\
\hline Variable & Model 1 & Model 2 \\
\hline Intercept & $27.99^{*}$ & $24.77^{*}$ \\
GPA & $-6.67^{*}$ & $-6.66^{*}$ \\
Dummy variable & $5.38^{*}$ & $5.85^{*}$ \\
Freshman & -1.31 & \\
Sophomore & -1.13 & \\
Junior & & \\
Dummy variable & -1.03 & \\
Traditional & & \\
Dummy variable & 1.37 & \\
Female & & \\
Dummy variable & -1.17 & \\
White & 0.63 & \\
Black & -2.32 & \\
Asia & & \\
Dummy variable & -1.93 & \\
US & 0.01 & \\
Study time & $11.88 \%$ & \\
\hline Adj. R $^{2}$ & & \\
* Significant at 1 percent significance level & & \\
\hline
\end{tabular}

* Significant at 1 percent significance level

\section{CONCLUSIONS}

Overall, students in this study overestimated their final exam performance by 5.55 points. Even after excluding 79 of the worst predictors, the rest of the sample still overpredicted their final scores by 2.03 points, which is statistically significant at the one percent level. Data show that a total of $63(11.35 \%)$ of the student-tests were failed. However, only one respondent correctly predicted failure. It appears that students are disinclined to admit that they may fail a final exam and display unrealistic optimism for a passing score. 
There were 16 respondents, with the average GPA of 2.93, who predicted earning perfect scores. However, their average actual score is only 80.13 (and two of these students actually failed their tests). This provides additional evidence that students have unrealistic optimism.

Freshmen, with little experience in the college classroom, have a stronger tendency to overestimate their performance. On average, they spent less time preparing for their final exams, expected more, and actually made less than students with more college experience. They overpredicted their grade by almost a letter grade.

Finally, analysis reveals that overall student overestimation may be due to students' incompetency to judge their own performance. Students with cumulative GPAs of 2.5 and below display the poorest ability to predict their grades. This group of students had the lowest expectation of 78.05 and the lowest performance of 67.70 , but the highest overestimation of 10.35. The expectations and actual scores go up monotonically as students GPA increase while the overprediction of final scores declines. Students with GPAs of 3.5 to 4.0 most accurately estimated their performance with the estimation error of less than half a point. These findings are consistent with the incompetency theory.

The results of this study may provide some insight for instructors. While working with students, it is important to realize that students tend to overestimate the scores that will be earned on pending tests. Whether due to unrealistic optimism or to an inability to recognize their own lack of preparation, unexpected results can be discouraging to students. Recognizing this phenomenon may be the first step in helping students learn how to better prepare for examinations. Understanding this phenomenon may eventually help educators reduce attrition and ultimately increase graduation rates.

\section{AUTHOR INFORMATION}

Terrye A. Stinson is the L.J. Blanchard Professor of Accounting at Southern Arkansas University. She earned her DBA from Louisiana Tech University. Stinson is a certified public accountant and a current member of the Arkansas State Board of Public Accountancy. Her research interests include financial accounting and strategies for effective teaching.

Xiaofeng Zhao is an associate professor of finance at Southern Arkansas University. He received his Ph.D. from Mississippi State University. His research interests include asset valuation, initial public offering, and effective teaching.

\section{REFERENCES}

1. Alicke, M., M. Klotz, D. Breitenbecher, T. Yurak, \& D. Vredenburg (1995) Personal contact, individuation, and the better-than-average effect, Journal of Personality and Social Psychology 68 (5): 804-825

2. Astin, A. W. (1975) Preventing students from dropping out, San Francisco: Jossey-Bass

3. Brown, J. D. \& F. M. Gallagher (1992) Coming to terms with failure: Private self-enhancement and public self-effacement, Journal of Experimental Social Psychology 28: 3-22

4. Clayson, D. E. (2005) Performance overconfidence: Metacognitive effects or misplaced student expectation? Journal of Marketing Education 27 (2): 122-129

5. Dunning, D., J. A. Meyerowitz, \& A. D. Holtzberg (1989) Ambiguity and self-evaluation: The role of idiosyncratic trait definitions in self-serving assessments of ability, Journal of Personality and Social Psychology 57 (6) 1082-1090

6. Fedor, D. B., R. M. Buckley, \& W. D. Davis (1997) A model of the effects of realistic job previews, International Journal of Management 14: 211-221

7. Grimes, P. W. (2002) The overconfident principles of economics student: An examination of a metacognitive skill, Journal of Economic Education 33 (1): 15-30

8. Kennedy, E. J., L. Lawton, \& E. L. Plummee (2002) Blissful ignorance: The problem of unrecognized incompetence and academic performance, Journal of Marketing Education 24 (3): 243-52 
9. Koku, P. S., \& A. A. Qureshi (2004) Overconfidence and the performance of business students on examinations, Journal of Education for Business 79 (4): 217-224

10. Kruger, J., \& D. Dunning (1999) Unskilled and unaware of it: How difficulties in recognizing one's own incompetence lead to inflated self-assessments, Journal of Personality and Social Psychology 77 (6): 1121 1134

11. Mangum, W., D. Baugher, J. Winch, \& A. Varanelli (2005) Journal of Education for Business 80(4): 218221

12. Murtaugh, P., L. Burns, \& J. Schuster (1999) Predicting the retention of university students, Research in Higher Education 40(3): 355-371

13. Newlon, L. L., \& G. H. Gaither (1980) Factors contributing to attrition: An analysis of program impact on persistence patterns, College and University 55: 237-251

14. Robertson, L.S. (1977) Car crashes: perceived vulnerability and willingness to pay for crash protection, Journal of Community Health 3: 136-141

15. Tinto, V. (1993) Leaving college: Rethinking the causes and cures of student attrition, Chicago, The University of Chicago Press

16. Weinstein, N (1980) Unrealistic optimism about future life events, Journal of Personality and Social Psychology 39 (5): 806-820

\section{NOTES}

